\title{
The Environmental, Social and Governance (ESG) Responsibilities of Landscape Architecture Firms
}

\author{
Xinying Zhang ${ }^{1}$, Cun Zhou ${ }^{2, *}$, and Shiyun Zhang ${ }^{2}$ \\ ${ }^{1}$ College of Landscape Architecture, Sichuan Agricultural University, Chengdu 611130, P.R. China \\ ${ }^{2}$ School of Economics and Management, Chongqing University of Posts and Telecommunications, Chongqing 400065, P.R. China
}

\begin{abstract}
ESG performance has a positive influence on the long-term sustainable development of both the firm and the society. LA is concerned about the relationship among humans, the buit, and nutural environments, so it is of especial importance to study what LA firms are supposed to do in ESG practice. This paper made a detailed discussion about each of the ESG responsibilities of LA firms respectively in accordance with the distinctive firm characteristics of the LA industry. This study might have two possible implications for the literature on ESG: (1) an industry-based approach to the study of ESG performance is of theoretical and realistic significance; and (2) ESG responsibilities are worthy of attention for the study of LA firms.
\end{abstract}

\section{Introduction}

ESG represents environmental, social, and governance respectively. ESG implies different literate meanings standing from different perspectives. From the perspective of the investor, ESG refers to a firm's performance on environmental, social, and governance issues, hence the ESG performance. As for investors, ESG refers to an investment criterion that socially conscious investors use to screen potential investments. Environmental criteria consider how a firm performs as a steward of nature. Social criteria examine how it manages relationships with employees, suppliers, customers, and the communities where it operates. Governance deals with a firm's leadership, executive pay, audits, internal controls, and shareholder rights ${ }^{\mathrm{a}}$.

ESG investing evolves from socially responsible investing (SRI) which is also termed as mission investing, ethical investing, sustainable investing, or green investing. It can be traced back to as early as the $18^{\text {th }}$ century when some religious groups prevented their believers from being involved in such businesses as tobacco, alcohol, gambling, and weapons, because such businesses were viewed as being against their religious ethical beliefs. Social concern became an investing dimension for investors. Towards the 1990s, rapidly developing economy worldwide has increasingly deteriorated the global environment. Environmental issues such as global warming and environmental pollution have become a growing concern for investors and the public in general, and environmental protection concern was thus incorporated into the investing

\footnotetext{
${ }^{a}$ https://www.investopedia.com/terms/e/environmental$\underline{\text { social-and-governance-esg-criteria.asp }}$
}

standards. As numerous companies went bankrupt during the period of the Asian financial crisis which occurred in 1998 and various scandals such as in Enron or WorldCom were exposed in the early $21^{\text {st }}$ century, the significance of strong governance has attracted increased attention from the government, academics and practioneers. As a consequence, corporate governance was added as a new dimension into the domain of responsible investing. In 2006, the United Nationssupported Principles for Responsible Investment (UN PRI) was proposed by Kofi Annan, former UN secretary- general, and established under the joint efforts of the United Nations Environment Programme Finance Initiative (UNEP FI) and the United Nations Global Compact (UNGC). It works to understand the investment implications of environmental, social and governance (ESG) factors and to support its international network of investor signatories in incorporating these factors into their investment and ownership decisions. Up to date, UN PRI has possessed over 2300 signatories including dozens of Chinese investment funds from more than 50 countries and managed over 80 trillion US dollars of assets $^{\mathrm{b}}$.

On September 30, 2018, China Securities Regulatory Commission issued Code of Corporate Governance for Listed Companies in China. Chapter 6 of the Code stipulates that listed companies should concern about such issues as environmental protection and public charity and value corporate social responsibilities while pursue the maximization of shareholder interests. This signifies the establishment of ESG information disclosure framework. On November 13, 2018, Asset Management Association of China issued the Research

\footnotetext{
${ }^{\mathrm{b}}$ https://www.unpri.org/pri/about-the-pri
}

\footnotetext{
* Corresponding author: zhoucun1995@163.com
} 
Report on ESG Evaluation System for Listed Companies in China. The Report provides a guideline for institutional investors to engage in green investment and practice the ESG investment principles.

Currently, growing numbers of financial institutional investors, both domestic and international, are practicing the ESG investing. They prefer to invest in those targets in their investment portfolio which capture a high proportion of green sales or are capable of maintaining a sustainable development.

Under the great pressures from ESG investing, firms are obliged to concern about environmental, social, and governance issues during their operation. From the perspective of the firm, ESG means what a firm is supposed to do in regard to environmental, social, and governance issues, hence the ESG responsibilities. ESG responsibilities have become an increasing concern for governments, regulatory bodies, and investors. Under such background, this paper attempts to explore how landscape architecture (hereafter abbreviated as LA) firms should perform their environmental, social, and governance responsibilities respectively so as to achieve sustainable development.

\section{Literature review}

Most existing literature focuses on the respective influence of environmental, social and governance performances on corporate value separately. The conclusions are inconsistent. Some scholars maintained that environmental performance has a positive effect on corporate value (Hu, 2012; $\mathrm{Lu}$ and Jiao, 2011), while some other argued that environmental performance has a negative effect on corporate value (Filbeck and Gorman, 2004). Chopra and $\mathrm{Wu}$ (2016) studied the environmental performance of companies in the computer and electronic industries and found that good environmental performance helps to improve long-term corporate performance. Kassinis and Soteriou (2003) found that good environmental performance is contributive for the firm to improve its sales, market share, and profitability and helps to stimulate market demands and customer satisfaction.

In terms of the effects of corporate social responsibilities on corporate performance, Surroca et al. (2010) and Kim and Kim (2014) argued that corporate social responsibilities have a positive correlation to corporate performance, Vance (1975) and Lerner (1994) concluded that corporate social responsibilities have a negative correlation to corporate performance, and Mcwilliams and Siegel (2001) found no relationship between corporate social responsibilities and corporate performance. As the relationship between corporate governance and corporate performance, too many scholars like Aldamen (2019), Li and Qiu (2010), and Li and Sun (2007) have found evidence that good corporate governance helps to improve corporate performance and value and facilitate firm's sustainable growth. Thus, this paper does not attempt to spend any more chapters on it.

In recent years, there have been a growing number of literatures on the relationship between ESG performance and corporate financial performance. Velte (2017) found that ESG performance have a positive effect on ROA based on a study of 412 listed companies in German.

Dimson et al. (2015) found that ESG expenditures are able to effectively reduce the overall financial costs. Ghoul et al. (2017) studied the relationship between ESG performance and market capitalization of compnies from 53 countries and found that ESG performance helps to reduce financing costs

Nevertheless, firms in one industry have different characteristics from those in another industry, and the industry differentiation is likely to have an effect on the components of ESG responsibilities as well as their influence on corporate performance. Besides, the governmental fiancé policies, interest rate policies, and industry policies and other external environmental factors have different effects on different industries. Thus, it is of special realistic significance to study the effects of ESG responsibilities on corporate performance from the perspective of the firm according to the distinctive industry attributes. Unfortunately, few studies of the effects of ESG performance on corporate financial performance have been made according to the distinctive characteristics of a certain industry.

Thus, this paper intends to analyze the components of ESG responsibilities of LA firms based on the unique firm characteristics of the LA industry. It will be hopefully contributive to enrich the literatures on ESG and LA firms.

\section{Environmental responsibilities of LA firms}

Landscape architecture is a professional design discipline that addresses both the built and natural environments. It focuses on the design, analysis, and planning of outdoor spaces across a wide range of scales, with the intent of creating places that are both meaningful and functional ${ }^{c}$. In this sense, environmental responsibilities are especially important to LA firms. In some sense, LA firms are supposed to shoulder greater responsibilities of creating a better living environment for mankind than any other firms. Generally speaking, LA firms are supposed to take the following three kinds of responsibilities in regards to environmental protection.

\subsection{Reducing environmental pollution}

The LA firm is supposed to take reduction of environmental pollution into consideration during the process of designing and planning LA products. Ornamentation plants are an important component of LA. The LA firm may train its landscape architects to be environmentally conscious. During the process of LA design, landscape architects are supposed to make a combined use of a variety of plants according to each

\footnotetext{
${ }^{\mathrm{c}}$ http://www.washington.edu/students/gencat/academic/1 arch.html
} 
plant's unique characteristics such as its growth height, demands for lighting, requirements on the soil, and adaptability to the topography. Proper ornamentation plants help to reduce water and air pollution and enable LA design products to be both aesthetic and environmentally friendly. Furthermore, landscape architects are expected to reduce the use of lighting ornamentation in their products whenever possible with an aim to saving energy consumption and thus creating a low-carbon living environment.

\subsection{Preserving historical and cultural relics}

During the development process of the national economy in the past decades of years, some of the Chinese historical and cultural relics have been unmercifully destroyed, leaving an unforgettable pain for the future generations. To prevent this from happening again, LA firms have the mission of preserving historical and cultural relics and proposing protective policies for the governmental regulatory agencies concerned. During the LA design process, LA firms need to keep an eye on both preserving historical and cultural relics and improving the surrounding environments. In this regard, Suzhou Gardens have set a good example for LA firms, indicating that well-designed LA products are capable of bringing in great economic benefits as well as preserving historical and cultural relics.

\subsection{Improving urban ecological environment}

One of the important functions of LA is ecological restoration, an instrument by which to improve urban ecological environment. In general, LA firms need to concern about ecological restoration and put LA planning into the larger urban and rural planning during the LA design process. Specifically speaking, LA firms are expected to produce various ecological design products such as wetland parks, green lands, and earthscape with the function of ecological restoration so as to maintain a sustainably harmonious development between the built and the natural environments.

\section{Social responsibilities of LA firms}

Carroll (1991) argued that four kinds of social responsibilities constitute total CSR, as shown in the following four-level pyramid of corporate social responsibility.

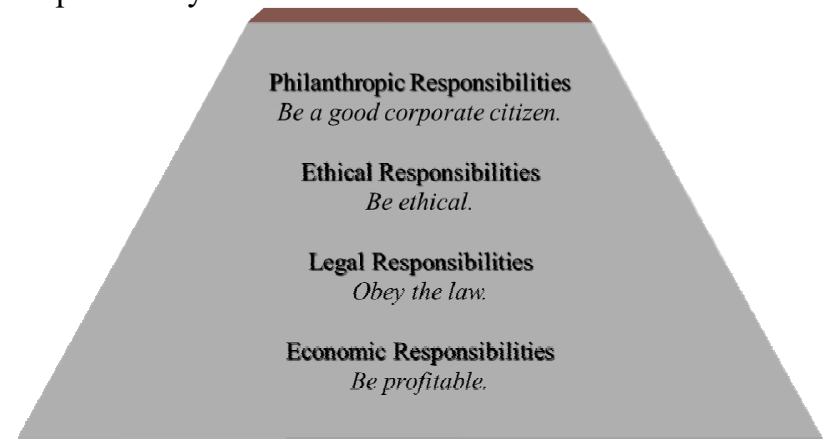

Fig.1. the Pyramid of Corporate Social Responsibility

Source: A. B. Carroll. The Pyramid of Corporate Social Responsibility: Toward the Moral Management of Organizational Stakeholders [J]. Business Horizons, July/August: 39-48 (1991).

Hence, this paper attempts to discuss the four kinds of social responsibilities of LA firms respectively.

\subsection{Economic responsibilities of LA firms}

As can be seen from Fig. 1, a firm's primary responsibility is to make profits, i.e., the economic responsibility is the basic building block upon which all other responsibilities are predicated. The economist and Nobel laureate Milton Friedman also argued that the social responsibility of business is to increase its profits (Friedman, 1970).

As mentioned in Carroll (1991), without the economic responsibility, all other responsibilities become moot consideration. The same goes true for LA firms. Hence, the LA firm's economic responsibility is to maximize profits for its shareholders by providing competitive products and services that cater to its customers' demands. In other words, a LA firm is expected to provide its customers with either low-cost or differentiated LA design products to make acceptable profits based on an in-depth market research on its customers' individual preferences to the LA design.

\subsection{Legal responsibilities of LA firms}

As can be seen from Fig. 1, the economic responsibility is the foundation, without which firms cannot survive on the market. Right above the economic responsibility is the legal responsibility which means obeying the law. Thus, the LA firm is required to comply with the governmental laws and regulations. That is to say, LA firms are expected to make profits lawfully. Additionally, LA firms are also expected to pay taxes as stipulated by the governmental laws concerned. Violation of the law is bound to trigger more strict supervision and more severe punishments from the governmental regulatory bodies, a negative consequence that will finally increase the firm's overall costs.

\subsection{Ethical responsibilities of LA firms}

The LA firm is not an independent entity responsible only for its shareholders but also has an obligation to the larger society. As shown in Fig.1, firms are expected to take ethical and philanthropic responsibilities which rest on the top of legal responsibilities. In his later work, Carroll incorporated the philanthropic responsibility into the ethical responsibility. For this reason, we will not devote a special section to philanthropic responsibilities of LA firms but incorporate them into ethical responsibilities of LA firms. As explained in Carroll (1991), the ethical responsibility involves doing what is 
right, just, and fair, and avoiding or minimizing harm to its stakeholders. Put it another way, the LA firm is expected to go beyond making profits for its shareholders alone to include meeting and improving the demands of every stakeholder. Stakeholders affect the LA firm's corporate performance. If the LA firm takes any actions unethical to its stakeholders, they would respond by taking some measures to protect their own interests, and this would put the LA firm under pressure. Thus, to relieve pressures from the stakeholders, the LA firm is obliged to do right things to its stakeholders. For example, the LA firm is expected to make efforts to create a satisfactory working environment for its employees and improve their salary and welfare so as to enhance employees' morale and productivity. For customers, the LA firm is expected to make an in-depth study of their individual demands, provide customized quality LA design products at low price, and establish and maintain a good relationship with them. In terms of competitors, the LA firm is expected to compete in a fair manner instead of taking some unethical actions such as slander and stealing competitive intelligence by hacking. As for suppliers, LA firms are supposed to pay money for the parts purchased in time as contracted. In terms of the community where they operate, LA firms are expected to take active part in and support community activities by donating capitals or materials.

\section{Governance responsibilities of LA firms}

Corporate governance refers specifically to the set of rules, controls, policies, and resolutions put in place to dictate corporate behavior. Corporate governance essentially involves balancing the interests of a company's many stakeholders, such as shareholders, senior management executives, customers, suppliers, financiers, the government, and the community. The board of directors is pivotal in governance ${ }^{\mathrm{d}}$. Based on an empirical study of the companies listed in FTSE4Good Bursa Malaysia from the year 2012 to 2016, Ismail et al. (2019) found that ESG practices have a significantly positive correlation to board size, board diversity, board independence, i.e., the larger the board size, the better the performance of ESG practices in that organizations; the higher level of board diversity will give favourable impacts toward the ESG practices among the companies; and the higher level of independent directors in the board gives advantages to the companies in the ESG aspect. Thus, it is crucially important for LA firms to esblaish a well-structured board of directors. LA firms are supposed to enlarge the board size and increase the board diversity whenever possible, as diverse backgrounds and experiences are contributive to improve corporate value and performance. To do so, LA firms may endeavor to employ distinguished experts or sholars with rich expertise on environmental protection, corporate social responsibility, and corporate governance

dhttps://www.investopedia.com/terms/c/corporategovern ance.asp as outside independent directors. Such independent directors are able to propose valuable suggestions and guidlines for LA firms to perform well in ESG practice, and this is helpful for the improvement of the firms' ESG performance. LA deals with the relationship among humans, the built and natural environments, so it is especially important for LA firms to perform well in environmental protection practice. LA firms may even invite environmental protection scholars to inspect their LA design products from the perspective of environmental protection. They may also recruit a certain proportion of employees majoring in environmental protection or similar areas whose task is to collaborate with landscape architects so as to enable the LA design products to be environmentally feasible. In addition, the LA firm is expected to set an Ethics Committee, which is responsible for the firm's ethical operation, under the board led by a chief ethical officer, which in turn helps to improve the firm's ESG performance.

In addition to the board, a well-designed compensation system is another important component of corporate governance. LA firms are supposed to establish an effective compensation system for both management and landscape architects in the light of the unique job characteristics in the LA industry. With a proper compensation system, landscape architects can be highly motivated to produce fruitful LA design products that are both cost-effective and environmentally friendly, a positive consequence that helps to facilitate the sustainably harmonious development between the firm and the natural environments.

Information disclosure is also an important component of corporate governance. At present, ESG information disclosure is not mandatory in China mainland except in Hong Kong. In 2015, the Stock Exchange of Hong Kong (SEHK) upgraded the Guideline for Environmental, Social, and Governance Reports issued in 2012 to a higher standard of comply or explain. Worldwide, an increasing number of stock exchanges start to compel their listed companies to disclose ESG reports. To achieve good ESG performance, LA firms can volunteer to disclose their ESG information in their annual reports. In this way, LA firms may put themselves under supervision by investors and the general public. Such behaviour is probably disadvantageous in the short term but is contributive for the firm's long-term sustainable development.

\section{Implications and Conclusions}

LA is concerned about the relationship among humans, the buit, and nutural environments, so it is of especial importance to study what LA firms are supposed to do in ESG practice. Good ESG performance helps to reduce financing costs, improve corporate image and reputation, enhance customer satisfaction, facilitate sales, increase corporate performance and value, and attract potential investors, which is contributive for the firm's long-term sustainable development. Consequently, LA firms are supposed to make best efforts to perform well in ESG 
practice so as to enable both themselves and the society to achieve a long-term sustainable development, as dedicated by the nature of LA. For this reason, this paper has made a detailed discussion about each of the ESG responsibilities of LA firms respectively in accordance with the distinctive characteristics of the LA industry. This study might have two possible implications for the literature on ESG: (1) an industry-based approach to the study of ESG performance is of theoretical and realistic significance; and (2) ESG responsibilities are worthy of attention for the study of LA firms.

\section{Acknowledgment}

We would like to thank the anonymous reviewers for their valuable suggestions. Financial supports from Chongqing Social Science Found (Project\#2018YBGL079) and Chongqing Scientific Research Innovation Foundation for Graduate Students (Project\# CYS18255) are also acknowledged.

\section{References}

1. A. B. Carroll. The Pyramid of Corporate Social Responsibility: Toward the Moral Management of Organizational Stakeholders[J]. Business Horizons, July/August:39-48 (1991)

2. A. M. Ismail, Z. H. M. Adnan, F. M. Fahmi, F. Darus, C. Clark. Board Capabilities and the Mediating Roles of Absorptive Capacity on Environmental Social and Governance (ESG) Practices[J]. International Journal of Financial Research, 10(3):11-30 (2019)

3. A. Mcwilliams, D. Siegel. Corporate Social Responsibility: A Theory of the Firm Perspective[J]. Academy of Management Review, 26(1):117-127 (2001)

4. D. L. D. Lerner. Pollution, Profits, and Stakeholder: The Constraining Effect of Economic Performance on CEO Concern with Stakeholder Expectations[J]. Journal of Business Ethics, 13(9):701-711 (1994)

5. E. Dimson, O. Karakas, X. Li. Active Ownership[J]. Review of Financial Studies, 28(12):3225-3268 (2015)

6. G. Filbeck, R. F. Gorman. The Relationship Between Environmental and Financial Performance of Public Utilities[J]. Environmental \& Resource Economics, 29:137-157 (2004)

7. G.I. Kassinis, A.C. Soterious. Greening the Service Profit Chain: the Impact of Environmental Maanagement Practice $[\mathrm{J}]$. Production and Operations Management, 12:386-403 (2003)

8. H. Aldamen, K. Duncan, S. Kelly, and R. Mcnamara. Corporate Governance and Family Firm Performance During the Global Financial Crisis[J]. Accounting and Finance, (2019).

9. J. Lu, S. Jiao. Empirical Study on the Relations among Environmental Disclosure, Environmental Performance and Financial Performance[J]. Journal of Shanxi Finance and Economics University, 33(1): 109-116 (2011) (in Chinese)

10. J.Surroca, J.A.Trib, S.Waddock. Corporate Responsibility and Financial Performance: The Role of in Tangible Resources[J]. Strategic Management Journal, 31(5):463-490 (2010)

11. M. C. Kim, Y. H. Kim. Corporate Social Responsibility and Shareholder Value of Restaurant Firms[J]. International Journal of Hospitality Management, 40:120-129 (2014)

12. M. Friedman. The Social Responsibility of Business is to Increase Its Profits [N]. New York Times, September 13: 122-126 (1970)

13. P.Velte. Does ESG performance Have an Impact on Financial Performance? Evidence from Germany[J]. Journal of Global Responsibility,8(2):169-178 (2017)

14. Q. Hu. Research on Relationship Between Environmental Performance and Financial Performance of Chinese Listed Companies[J]. China Population, Resources and Environment, 22(6):2332 (2012) (in Chinese)

15. S. Chopra, P.J. Wu. Eco-activities and Operating Performance in the Computer and Electronics Industry[J]. European Journal of Operational Research, 248:971-981 (2016)

16. S. E. Ghoul, O. Guedhami, Y. Kim. Country-Level Institutions, Firm Value, and the Role of Corporate Social Responsibility Initiatives[J]. Journal of International Business Studies, 48(3):360-385 (2017)

17. S. G. Vance. Are Socially Responsible Corporations Good Investment Risks?[J]. Management Review, 64(8):19-24 (1975)

18. W. Li, A. Qiu. Governance Transition of Chinese Private Firms, Political Connections and Firm Performance[J]. Journal of Management Science, 23(4):2-14 (2010)

19. W. Li, W. Sun. An Empirical Study on Accumulation Effect of Board Governance upon Corporate Performance: The Evidence from China Listed Companies[J]. China Industrial Economy, 237(12):77-84 (2007) 